\title{
A ECOLOGIA CRÍTICA NUM DIÁLOGO COM A ECOLOGIA INTEGRAL DA ENCÍCLICA PAPAL LAUDATO SI CUIDANDO DA CASA COMUM
}

\author{
CRITICISM ECOLOGY IN A DIALOGUE WITH THE FULL ECOLOGY \\ LAUDATO SI PAPAL ENCYCLICAL ITSELF - CARING FOR COMMON HOME
}

\author{
${ }^{1}$ Jeaneth Nunes Stefaniak \\ ${ }^{2}$ João Luiz Stefaniak
}

\section{RESUMO}

A questão ambiental está na ordem do dia na agenda mundial, por conta da emergência ecológica que vem se tornando cada vez mais aguda. Em maio de 2015 o Papa Francisco publica a Encíclica denominada Laudato si: Cuidando da Casa Comum, em que enfrenta a temática ambiental, pautando esta crise como derradeira, da humanidade. O documento atribui responsabilidades pela degradação ambiental às atividades humanas, fazendo crítica contundente ao sistema econômico, enumera o que considera os aspectos mais graves da degradação ecológica, demonstra a ineficácia das ações gestadas internacionalmente para construir um mundo sustentável para as gerações presentes e futuras e, por fim, propõe a construção do que chamou de ecologia integral, agregando conceitos do socioambientalismo e ecossocialismo, fazendo, com estas correntes ecologistas, um diálogo conceitual. Assim, este estudo visa analisar o documento oficial da Igreja Católica e evidenciar as aproximações com as conclusões e propostas da ecologia crítica.

Palavras-chave: Sustentabilidade, Crise ecológica, Ecologia integral

\footnotetext{
${ }^{1}$ Doutora em Direito pela Pontifícia Universidade Católica do Paraná - PUC, Paraná (Brasil). Professora de Direito Civil pela Universidade Estadual de Ponta Grossa - UEPG, Paraná (Brasil). E-mail: jeaneth@bol.com.br

${ }^{2}$ Doutorando em Geografia pela Universidade Estadual de Ponta Grossa - UEPG, Paraná (Brasil).

E-mail: joaoluiz@stefaniak.com.br
} 


\begin{abstract}
The environmental issue is on the agenda on the world, due to the ecological emergency that is becoming increasingly acute. In May 2015 the Pope Francisco publishes the encyclical called Laudato si: Caring for the Common House, in facing environmental issues, basing this ultimate crisis of humanity. The document assigns responsibility for environmental degradation to human activities, causing blunt criticism of the economic system, describes what he considers the most serious aspects of ecological degradation, demonstrates the ineffectiveness of gestated actions internationally to build a sustainable world for present and future generations and finally, proposes the construction of what he called integral ecology, joining the concepts of socio-environmentalism and eco-socialism rendering with these chains ecologists, a conceptual dialogue. This study aims to analyze the official document of the Catholic Church and highlight its work with the conclusions and proposals of critical ecology.
\end{abstract}

Keywords: Sustainability, Ecological crisis, Integral ecology 


\section{INTRODUÇÃO}

A questão ambiental está contemporaneamente no ápice das prioridades mundiais, e vem sendo considerada com a mais grave crise que a humanidade já enfrentou. Porém, apesar de estar pautada na agenda mundial, não equivale a adoção de medidas para enfrentar eficazmente os reflexos da degradação ambiental. A ineficácia das ações de combate a crise, tem uma justificativa, que é a impossibilidade de frear o sistema metabólico do capitalismo, que se reproduz de modo incessante e supera qualquer barreira ao seu avanço, seja qual for o obstáculo.

Nesta linha de raciocínio, por conta da agudização da crise ecológica, evidenciadas pelos desastres ambientais e, a ineficácia das propostas que almejam buscar a sustentabilidade ambiental, é que surgem as reflexões de ecologistas denominados de socioambientalistas e dos ecossocialistas, que ao formularem suas análises desqualificam a maioria das propostas conservacionistas, porque todas sem exceção, submetem o meio ambiente ao sistema econômico, colocando-o como insumo do crescimento, desconsiderando os fatores sociais e ambientais, e a agressão sem precedentes à natureza.

Para instigar o debate mundial sobre o meio ambiente, o Papa Francisco, publica a Encíclica Laudato Si - Cuidando da Casa Comum, onde elabora profunda reflexão sobre a crise ambiental e trilha pelo mesmo caminho dos ecologistas chamados críticos, chegando às mesmas conclusões: que somente com a superação do modelo econômico vigente se poderá buscar a sustentabilidade. Assim, se analisa a Encíclica publicada em maio deste ano em um diálogo com a ecologia crítica, demonstrando as aproximações possíveis deste importante documento e suas propostas para a construção da sustentabilidade.

\section{As causas da crise ambiental}

A degradação ambiental começa a ganhar proporção com advento do sistema econômico capitalista e quando este se torna hegemônico, no final do século XX, a questão ecológica se agrava. O capitalismo se globaliza, porém, os padrões de vida e de consumo dos países desenvolvidos não podem e nem devem ser universalizados, embora justamente esta crença ideológica é o que alimenta a ação dos países não desenvolvidos ou em desenvolvimento. 
A origem antropocêntrica da crise ambiental, é constatada pelos ecologistas críticos, e pelos movimentos ambientalistas que incessantemente demonstram que os desastres ambientais cada vez mais comuns, podem se transformar em problemas insuperáveis e, nenhuma ação colocada em prática até os presentes dias foram suficientes para impedir o avanço da degradação.

A Encíclica papal publicada em 24 de maio de 2015, denominada Laudato si Cuidando da Casa Comum, em que o Papa Francisco, enfrenta a questão ambiental, se inicia fazendo a importante constatação de que a crise ecológica é causada pelas atividades humanas, pela característica produtivista da economia capitalista, que impõe um consumo irresponsável, alavancado pelo mercado global, por meio de necessidade criadas e disseminadas pelo império da informação e da publicidade no mundo globalizado, degradada o meio ambiente e o ser humano.

As Encíclicas papais historicamente influenciaram os setores da sociedade, permitindo o surgimento de teorias fundamentais para a construção da ordem políticojurídica contemporânea, como por exemplo a teoria funcionalista da propriedade, de origem claramente eclesiástica e dos princípios gerais do Direito do Trabalho e do Direito Previdenciário, cuja Encíclica Rerum Novarum - sobre a situação dos trabalhadores, foi de inegável importância para a criação de novos preceitos nestas áreas.

Assim este documento oficial da Igreja Católica, quando assume solenemente as críticas ao modo de vida contemporâneo, possui grande repercussão, e pode atuar decisivamente na elaboração de políticas internacionais com outras características e força para modificar a rota do colapso ambiental.

A crise ecológica possui várias facetas e deve ser analisada sob a ótica dos recursos naturais renováveis e não renováveis, da adoção de matriz energética, grande responsável pela emissão de gases de efeito estufa e fator principal do aquecimento global. As formas de poluição e de utilização dos recursos naturais impõem o avanço da degradação e anunciam a possibilidade de colapso ambiental. A relação humana com seu ambiente é, de fato, condicionada pelo sistema produtivo. Assim, a geração de mercadoria, o consumo criado e ostentatório e a utilização irresponsável dos recursos naturais conduziram e conduzem à insustentabilidade ecológica. Esta mesma análise é feita na Encíclica ao abordar sinteticamente os variados aspectos da crise ambiental, apontando os graves pontos que estão conduzindo ao desastre ecológico, ou nas palavras do Papa, “o que está acontecendo com nossa casa comum”. 
A análise da Encíclica, se inicia a partir da reflexão sobre a poluição e as mudanças climáticas, os vários tipos de poluição afetam a todos indistintamente e vêm transformando o planeta num grande depósito de lixo, destruindo ecossistemas inteiros, por conta da necessidade expansionista da economia. O aquecimento do sistema climático e considerado de extrema gravidade, por proporcionar a elevação do nível dos oceanos e de fenômenos meteorológicos extremos, extinção da biodiversidade e eleva o número da população que passou a ser denominada de desabrigados ambientais. Segundo a Encíclica, o clima deve ser entendido como bem comum, um de todos e para todos ${ }^{1}$. Importante registrar, que a Encíclica ressalta que a causa do aquecimento global, é antropogênica, por conta da matriz enérgica adotada, da emissão de gases de efeito estufa, e do desflorestamento para finalidade agrícola.

Como segundo problema a ser enfrentado, sob a ótica do documento oficial da Igreja Católica, se elegeu a água. Já que a água potável, como recurso finito que é, e primordial para existência da humanidade, que vem sendo usada de modo desigual, já que o recurso hídrico foi largamente utilizado por países desenvolvidos e por setores mais aquinhoados economicamente na sociedade, de modo irresponsável, enquanto populações inteiras perecem pela falta de água para necessidades essenciais, se vitimizadas por doenças comuns como diarreia e cólera, elevando índices de mortalidade infantil.

Além da questão do uso irresponsável do recurso hídrico, a Encíclica papal enfrenta um outro aspecto ligado a água de grande relevância que é a privatização do uso da água, transformando este direito humano fundamental em mercadoria, neste ponto a constatação inevitável a que se chega, é que as disputas relativas ao controle da água, será a principal fonte de conflito mundial. Novamente a conclusão a que se chega, que os recursos hídricos escassos estão sendo ameaçados pela atividade humana, que segundo Francisco, no item 29 da Encíclica:

Em muitos lugares, os lençóis freáticos estão ameaçados pela poluição produzida por algumas atividades extrativas, agrícolas e industriais, sobretudo em países desprovidos de regulamentação e controles suficientes. Não pensamos apenas nas descargas provenientes das fábricas; os detergentes e produtos químicos que a população utiliza em muitas partes do mundo continuam a ser derramados em rios, lagos e mares.

\footnotetext{
${ }^{1}$ Item 23.
} 
E essa atitude irresponsável da humanidade, perseguindo o lucro e a satisfação imediata, é o que coloca a sobrevivência planetária em risco, é toda forma de vida que está em questão.

Dando seguimento a análise das questões ambientais, a Encíclica aborda a perda da biodiversidade. O desflorestamento para fins econômicos, leva a extinção de espécies e determina a impossibilidade de resolver problemas futuros, como por exemplo a cura de doenças. A conclusão de que a intervenção humana é profundamente danosa aos ecossistemas, tão nociva porque desconsidera a complexidade dos sistemas naturais, não só dos seres com maior visibilidade mas atinge igualmente a uma variedade enorme de microrganismos.

A substituição de florestas nativas por outras opções florestais ou mesmo por conta da monocultura, numa exigência do mercado mundial, produzem importante impacto ambiental que não se restringem a biodiversidade terrestre, mas também a marinha, transformando os oceanos em "cemitérios subaquáticos, despojados de vida e de cor" e conforme Francisco, no item 41 da Encíclica, este fenômeno deve-se à poluição que resulta do desflorestamento, da monocultura agrícola, de pesca predatória, de descarga de detritos industriais, agravam os problemas ambientais de forma considerável.

\section{O social e o ambiental aspectos indissociáveis}

Na leitura do problema ambiental, sob a ótica papal, se passa então a analisar a deterioração da qualidade de vida e a degradação social. Por constatar que a crise ecológica é originária das atividades humanas, do consumismo e da cultura do descarte, por conta do crescimento sem controle e planejamento dos núcleos urbanos, fonte de produção imensurável de todos os tipos de poluição e utilização desmedida dos recursos naturais, em especial a água potável.

Consecutivamente o documento papal registra a conclusão que a crise ambiental possui ligações diretas com a desigualdade no planeta, afirmando categoricamente que a questão ecológica produz efeitos muito mais devastadores aos pobres, os excluídos que são a maioria da população da Terra, conforme Francisco, 2015, item 48: 


\begin{abstract}
A deterioração do meio ambiente e a da sociedade afetam de modo especial os mais frágeis do planeta: Tanto a experiência comum da vida quotidiana como a investigação científica demonstram que os efeitos mais graves de todas as agressões ambientais recaem sobre as pessoas mais pobres» (...)O impacto dos desequilíbrios atuais manifesta-se também na morte prematura de muitos pobres, nos conflitos gerados pela falta de recursos e em muitos outros problemas que não têm espaço suficiente nas agendas mundiais.
\end{abstract}

Neste item a Encíclica analisa alguns temas polêmicos como a redução da natalidade, desqualificando o problema do aumento populacional, e afirma ser possível preservar a natureza mesmo nesta conjuntura, pois o problema não está ligado natalidade e sim ao consumismo exacerbado, falar em demografia é desviar do real problema a ser enfrentado. Aqui as conclusões do documento solene da Igreja Católica se aproximam do socioambientalismo, e fica claro que por esta concepção, o social e o ambiental estão unidos de forma definitiva.

O mito da dominação humana sobre a natureza surge contemporaneamente como a grande ameaça para a manutenção da vida em todas as suas formas. Enquanto os ecossistemas agonizam pelo progresso da acumulação material, surgem os movimentos ambientalistas que denunciam a gravidade do problema, com propostas de se deter o crescimento econômico para se deter a destruição ambiental. A desigualdade instalada globalmente, que divide o planeta em ricos e pobres - onde os abastados continuam a acumular riquezas e manter padrões insustentáveis de consumo, e os pobres globalizados desejam obter, ao menos, o direito de consumir -, a defesa ambiental é rechaçada. Nesse contexto nasce a ideia do desenvolvimento sustentável, havendo relativa unanimidade em torno dos valores que o conceito carrega, que, em tese, permitiria que a humanidade continuasse a se desenvolver, entretanto, em harmonia com o meio ambiente. Nesse contexto nasce a ideia do desenvolvimento sustentável, havendo relativa unanimidade em torno dos valores que o conceito carrega, que, em tese, permitiria que a humanidade continuasse a se desenvolver, entretanto, em harmonia com o meio ambiente.

\title{
4. A ineficácia das ações para conter a degradação ambiental
}

As construções doutrinárias ecologistas críticas, concluem que os projetos criados para conter a crise ambiental, não foram capazes de criar qualquer obstáculo ao avanço da degradação do meio ambiente, por todos estas propostas, foram gestadas no âmbito 
do sistema econômico e por ele subjugadas, mesmo a ideia do desenvolvimento sustentável. A despeito da axiologia de um desenvolvimento sustentável quatro décadas após o surgimento de seu conceito, este se mostrou ineficaz, insuficiente, impossível de ser universalizado e se tornou mais um mito no sistema produtor de mercadorias $^{2}$. O modo de produção, a propriedade privada e o consumo levam à contaminação e destruição ambiental, e este tripé não admite pensar o meio ambiente a não ser como mais uma mercadoria a serviço da reprodução do capital.

As propostas e políticas criadas, complementares ao desenvolvimento sustentável, não propõem a superação do modo de produção de mercadorias. Ao revés, se passou a tratar a natureza efetivamente como mercadoria. $\mathrm{O}$ fator ambiental começa a ser contabilizado como um custo, que precisa ser internalizado; assim, o conceito da internalização das externalidades negativas, da ciência econômica, aparece como importante componente para precificar os bens e recursos ambientais. Surgem, assim, os projetos de pagamento por serviços ambientais e, mesmo em face da polêmica que envolve tais intenções, encontram-se na ordem do dia e já vêm se transformando há algum tempo em leis ou políticas implementadas, ou em fase de implementação.

Complementado a ideia de internalizar as externalidades negativas, os custos ambientais, nasce a política tributária ecológica, com o objetivo de se estabelecerem tributos ambientais - as chamadas ecotaxas -, cujo objetivo é, a partir dela, criar um capitalismo limpo, ou como vem se divulgando, um movimento autodenominado “economia verde". Esclarece Lowi ${ }^{3}$ ser uma ilusão, pois arrecadar mais impostos não alterará a conexão entre produtivismo e capitalismo e, portanto, é impossível controlar os excessos do sistema produtivo. Arrecadar mais impostos pode equivaler, inclusive, a fazer concessões numa perspectiva do poluidor-pagador.

De modo equivalente a análise acima, constante das reflexões dos ecologistas críticos, a Encíclica aborda as reações à crise, e as considera fracas e insuficientes para combater a degradação, mesmo que o debate ambiental esteja pautado na agenda da política internacional, a submissão aos interesses econômicos tem preponderado e vencido todos os embates travados nos eventos mundiais sobre meio ambiente. Os esforços ambientalistas têm sucumbido ao poderio do sistema financeiro, dos poderosos grupos econômicos que destroem os recursos naturais. Até o presente momento, mesmo

2 MONTIBELLER-FILHO, Gilberto. O mito do desenvolvimento sustentável: meio ambiente e custos sociais no moderno sistema produtor de mercadorias. Florianópolis: Editora da UFSC, 2001.

3 LOWI, Michael. Ecologia e socialismo. São Paulo: Cortez, 2005, p.46. 
com todo acumulo cientifico acerca das questões ambientais, não fomos capazes de forjar uma saída para o desastre que se avizinha. A Encíclica defende a existência de um sistema normativo com eficácia tal que submeta todos os interesses à preservação do planeta, segundo Francisco, item 53: "Torna-se indispensável criar um sistema normativo que inclua limites invioláveis e assegure a proteção dos ecossistemas, antes que as novas formas de poder derivadas do paradigma tecno-econômico acabem por arrasá-los não só com a política, mas também com a liberdade e a justiça”, tudo em respeito às gerações futuras.

\section{A propriedade privada e o meio ambiente}

No subtítulo 6 do capítulo II, item 93, o documento papal, traz a perspectiva da propriedade privada e sua função social, tradição da Igreja Católica, que grandemente contribuiu para construção da doutrina funcionalista da propriedade. A inovação da abordagem de Francisco, é que ele defende a total submissão da propriedade privada aos bens universais, enquanto princípio maior. Nenhum interesse privado deve prevalecer, sobre o interesse comum, e a preservação da Terra é o interesse comum.

No capítulo II, item 102, metodologicamente a Encíclica volta a insistir na raiz humana dos problemas ecológicos, conforme Francisco, item 101:

Para nada serviria descrever os sintomas, se não reconhecêssemos a raiz humana da crise ecológica. Há um modo desordenado de conceber a vida e a ação do ser humano, que contradiz a realidade até ao ponto de a arruinar. Não poderemos deter-nos a pensar nisto mesmo? Proponho, pois, que nos concentremos no paradigma tecnocrático dominante e no lugar que ocupa nele o ser humano e a sua ação no mundo.

Neste ponto, ressalta que o crescimento econômico e tecnológico não veio acompanhado do desenvolvimento humano, por conta dos valores humanos ético-morais do homem moderno, justamente porque a propriedade privada, corolário da liberdade e esta por sua vez, valor essencial no sistema econômico-político, capitalista-liberal, não admite estabelecimento de regras, o redunda na visão egoística acerca dos bens comuns, para satisfação de interesses imediato, sob o signo do lucro, a despeito das necessidades da população e de seu futuro. 
Quais as possibilidades reais de mudanças de rumos? Segundo o documento papal, dentre elas, merece destaque a superação do paradigma homogêneo e unidimensional, imposto pela globalização, já que o mercado divinizado é o instrumento da degradação, deve-se resgatar modo de vida alternativos, conforme Francisco, item 111 da Encíclica:

Por exemplo, quando comunidades de pequenos produtores optam por sistemas de produção menos poluentes, defendendo um modelo não-consumista de vida, alegria e convivência. Ou quando a técnica tem em vista prioritariamente resolver os problemas concretos dos outros, com o compromisso de os ajudar a viver com mais dignidade e menor sofrimento. E ainda quando a busca criadora do belo e a sua contemplação conseguem superar o poder objetivador numa espécie de salvação que acontece na beleza e na pessoa que a contempla.

Apesar da visão metafórica, a ideia é de limitar a técnica e orientá-la para outra espécie de progresso e de interesses, que não só os econômicos.

\section{Uma ecologia integral pelo Papa Francisco}

Por fim, no capítulo IV, a Encíclica Papal conceitua "ecologia integral”, como aquela que inclui as dimensões, ambiental, econômica e social. O que é mais relevante neste conceito é a afirmação de que um conceito de ecologia honesto, deve confrontar o modelo de desenvolvimento, produção e consumo e, superá-lo se necessário for, em prol da sobrevivência da sociedade, conforme Francisco no item 138 da Encíclica:

A ecologia estuda as relações entre os organismos vivos e o meio ambiente onde se desenvolvem. E isto exige sentar-se a pensar e discutir acerca das condições de vida e de sobrevivência duma sociedade, com a honestidade de pôr em questão modelos de desenvolvimento, produção e consumo. Nunca é demais insistir que tudo está interligado.

A crise ambiental não se resolverá, sem o enfrentamento das outras dimensões, socioeconômica presentes, dada a interação dos sistemas. A fórmula para equacionar os problemas ecológicos, perpassa pela superação da questão social. Não é possível preservar a natureza, persistindo a exclusão social de milhões de pessoas. 
Ainda na perspectiva da ecologia integral, critica a chamada, automatização e homogeneização do modo de vida no planeta, em curso, em decorrência das inovações tecnológicas e da economia globalizada, e como alternativa o documento propõe uma humanização com respeito aos diversos saberes e culturas locais, nas palavras de Francisco, item 144 da Encíclica:

É preciso assumir a perspectiva dos direitos dos povos e das culturas, dando assim provas de compreender que o desenvolvimento dum grupo social supõe um processo histórico no âmbito dum contexto cultural e requer constantemente o protagonismo dos atores sociais locais a partir da sua própria cultura. Nem mesmo a noção da qualidade de vida se pode impor, mas deve ser entendida dentro do mundo de símbolos e hábitos próprios de cada grupo humano.

A ecologia integral é também uma ecologia humana, da vida cotidiana, de resgate de espaços públicos, que faz com que surjam nas pessoas o sentimento de pertencimento a um lugar e a partir daí, aflore o sentimento de preservação. No entanto, esta proposta, perpassa pelas políticas públicas que equacionem a questão da moradia e do transporte público, graves problemas sociais que produzem efeitos desastrosos ao meio ambiente.

Nesse contexto a proposta de uma nova ecologia, integral e integradora, tem como pressuposto o reconhecimento e efetividade dos direitos humanos fundamentais, porque o conceito de ecologia está vinculado à noção de bem comum. Os problemas dos excluídos dos bens terrenos, são geradores da impossibilidade de evitar a degradação ambiental, está tudo interligado, não só para a sociedade contemporânea, mas também para as gerações futuras.

Em síntese no conceito de ecologia integral, estão contidas as dimensões ambiental, social, econômica, cultural e humana, sem as quais a humanidade não será capaz de trilhar o caminho da preservação ambiental.

\section{A ecologia integral e propostas para além do capitalismo}

Após estabelecer o conceito de ecologia integral, a encíclica elabora algumas propostas de ações fundamentais para buscar a preservação ambiental; O diálogo internacional, superando a defesa de interesses unilaterais, em prol dos interesses comuns de todos os povos do planeta. Estabelecer novos projetos de agricultura sustentável, outra 
matriz energética, menos poluidora e mais eficiente, editar regras acerca da gestão dos recursos florestais e marinhos, além de possibilitar o acesso de água potável a todos os povos.

O documento papal reconhece a importância dos movimentos ecologistas e suas conquistas em prol da causa ambiental. Cita todos os eventos mundiais que estabeleceram normas internacionais, desde a Convenção de Estocolmo de 1972, a Rio 92, A convenção da Basileia, a Convenção de Viena, o Protocolo de Montreal, a Conferência das Nações Unidas - Rio + 20 e suas deliberações em torno da questão ambiental.

A ação voltada para internacionalizar custos ambientais, como a tentativa de reduzir a emissão de gases poluentes, recebem duras críticas, já que na prática acabaram por impor situações injustas aos países pobres e em desenvolvimento, que são penalizados com medidas drásticas, não responsabilizando efetivamente os países industrializados que foram os grandes responsáveis pela elevada emissão dos gases de efeitos estufa. Também recebe críticas a estratégia denominada de "créditos de carbono", que termina por criar uma nova forma de especulação, sob a bandeira da preservação ambiental, permite a manutenção do modo de vida consumista de algumas nações e de alguns setores da sociedade.

Na perspectiva internacional, a solução é o estabelecimento de acordos internacionais por força coercitiva, recrudescer as ações e sanções para os inadimplentes das obrigações ecológicas. Para isso é necessário maturar e tornar as organizações internacionais mais fortes e eficazes, sob pena das normas internacionais continuarem a não produzir qualquer efeito.

Outra ação de fundamental relevância para o enfrentamento da crise ambiental, se refere a perspectiva da ecologia humanista e cultural, voltada para o diálogo com as políticas nacionais e locais. O diálogo proposto, pressupõe o respeito aos saberes locais, a eficácia de uma regra se dá especialmente quando está enraizada na cultura do povo. Para além das deliberações internacionais, a preservação ambiental se vincula ao resgate das tradições e do modo de viver comunitário $^{4}$, a despeito da imposição da universalização do modo de viver globalizado. 
Tais propostas já fazem parte de projetos políticos de países como o Equador e a Bolívia, que adotam a doutrina do Bem Viver, onde a Terra - chamada de Pacha Mama ${ }^{5}$, é tratada como sujeito de direito e a proposta e o resgate e o respeito ao modo de vida tradicional dos povos andinos, em harmonia com a natureza, porque faz parte daquela cultura, daquele modo de viver.

A contundência da Encíclica Laudato si, se observa também quando critica as fórmulas de desenvolvimento sustentável, até então propostas, como forma de mascarar a manutenção do modo de viver capitalista, que não admite freios ao crescimento econômico, independentemente de quais sejam os obstáculos existentes, o mercado sempre os supera, mesmo que o custo socioambiental seja muito alto, o que importa é o lucro. E, para além dessa crítica questiona o valor supremo deste modo de vida, que é a liberdade. Coloca em questão qual tipo de liberdade ser defende, aquela que permite um número reduzido de setores da sociedade, possam usufruir de recursos de modo irresponsável, em detrimento do bem comum? Ao fazer tal crítica, o Papa Francisco aponta para a necessidade um novo estilo de vida, com a superação do paradigma consumista compulsivo criado pelo mercado.

Tais deliberações passam pelo enfrentamento corajoso com ações, que muitas vezes vão contrariar a economia de mercado, como por exemplo a retirada de produtos poluentes, mudança de matriz energética, rentáveis, mas arrasadoras do meio ambiente.

Por fim, a Encíclica Papal embora não se utilize do princípio idealizado no esteio do Direito Ambiental, do in dubio pro natureza ${ }^{6}$, fica evidente que a proposta do documento da Igreja Católica propõe a eficácia e efetividade deste princípio, como regra a ser seguida para qualquer empreendimento a ser realizado, sempre que houver dúvidas acerca dos benefícios, da utilidade para o bem comum, da violação dos bens ambientais, deve-se vetar a iniciativa, pois o econômico deve se submeter ao socioambiental. Aqui também é importante registrar que a Constituição do Equador e a Lei da Mãe Terra da Bolívia, dispõe como princípio fundamental daquele ordenamento jurídico o in dubio pro natureza, criando a defensoria da Mãe Terra, com importante órgão a tutelar os bens ambientais.

MARÉS, 2003, p. 11. Esclarece que diversas culturas consideram a Terra uma divindade e lhe dedicam tributo. Algumas a denominam de pai, pátria, e outras de mãe, Pacha Mama, que é como os quéchuas a chamam, porque a representam na forma de uma mulher que traz ao colo uma criança. 


\section{CONCLUSÃO}

A constatação da a causa antropogênica da crise ambiental, incrementada com a supremacia do sistema econômico capitalista, no final do século $\mathrm{XX}$, faz parte das conclusões dos ecologistas de orientação crítica, e também da Encíclica Papal, que condena a cultura do descarte adotada pela humanidade, por força do mercado produtor de mercadorias e indutor de uma cultura homogeneizada, em função do mundo globalizado.

As várias facetas da crise ambiental reclamam por ações contundentes e urgentes em prol da salvação do planeta. E as normas internacionais, com características de soft law, não dão conta de frear os ímpetos do mercado e da degradação ambiental. Há exigência de uma articulação internacional para uma ação efetiva que busque a desconstrução da racionalidade econômica, que trata a humanidade de modo homogêneo e transforma tudo em mercadoria.

A sustentabilidade ecológica exige a limitação ou, em alguns casos, até mesmo a vedação da utilização de recursos ambientais, especialmente os não renováveis. Essa perspectiva pressupõe ações no sentido de se modificarem os padrões de consumo e a matriz energética, inclusive com ações que levem em consideração o crescimento da população mundial e estabeleçam-se efetivos limites econômicos e sociais, o que antagoniza com a essência do sistema econômico.

A ascendência do sistema econômico produziu a crise ambiental e seu agravamento exigiu que se buscassem soluções; foi nesse contexto que se deu o surgimento do Direito Ambiental e do princípio da sustentabilidade. No entanto, desde seu advento, uma grande polêmica envolve o conteúdo conceitual da sustentabilidade ambiental, já que esta pode se constituir num entrave à expansão econômica. Na correlação de forças entre economia e meio ambiente, numa conjuntura de emergência social que pressionava por necessidades desenvolvimentistas, surge o que se pode chamar de sustentabilidade fraca, em que se dá a preponderância à dimensão econômica do conceito, que se globaliza como desenvolvimento sustentável.

A unanimidade em torno do conteúdo conceitual do desenvolvimento sustentável ocorria porque este parecia ser a saída para conciliar a manutenção da lógica do capital, seus fundamentos e valores, com a necessidade de controle da crise 
ecológica. Foi essa concordância generalizada em torno dessa possibilidade que levou à positivação do conceito de desenvolvimento sustentável; contribuiu para colocar a questão ambiental no foco de muitos debates acerca de políticas públicas, porém, evidentemente, foi absolutamente ineficaz para se impor globalmente, porque representaria uma limitação ao avanço da ordem reprodutiva capitalis ta, além de não eliminar as formas danosas da intervenção humana na natureza.

Assim, as poucas experiências de desenvolvimento sustentável mostraram-se tímidas e de pequeno impacto, não produzindo qualquer transformação efetiva.

O reconhecimento da ineficácia das propostas econômicas em torno do desenvolvimento sustentável conduziu à idealização de políticas voltadas para a monetarização da natureza, transformando-a em mercadoria, na lógica do sistema capitalista, com o objetivo de torná-la, juntamente a seus bens e seu metabolismo, atrativos para o mercado. Isso ocorreu com a privatização dos bens comuns e o consequente estabelecimento de um preço para o meio ambiente. Nesta perspectiva, então, trazer para a lógica reguladora do capital o mais emblemático problema enfrentado pelo sistema econômico. A finalidade da política de precificação da natureza é objetivamente colmatar as deficiências das políticas de desenvolvimento sustentável, complementando-as, e assim buscar a sustentabilidade ambiental e capitalista.

As medidas propostas para conter a crise ambiental podem ser designadas de marginais e necessariamente compatíveis com o modo de produção capitalista, e por exigência da visão fundamentalista mercantil, devem ir além, possuir ainda uma característica de ser benéficas ao sistema econômico, como no caso da criação de um mercado para bens e serviços ambientais. Dessa forma, as políticas ambientais, por serem compatíveis e favoráveis ao capitalismo, não se constituem em entraves e permitem ao capital prosseguir na sua rota sempre incontestável.

Em pleno século XXI e numa conjuntura de emergência ambiental, algumas propostas surgem oxigenando o debate sobre a sustentabilidade, algumas inclusive, envolvendo um projeto de ruptura com o modelo econômico vigente em prol da sobrevivência do planeta. Neste estado da arte, surge a Encíclica Laudato si Cuidando da Casa Comum, importante documento de autoria do Papa Francisco, onde enfrenta os temas relativos ao meio ambiente e a derradeira crise que assola a 
humanidade. A novidade da carta solene da Igreja Católica é a aproximação com as constatações formuladas pela ecologia crítica, propugnando uma superação do modo de viver globalizado e homogeneizado pelo mercado produtor de mercadorias. Reclamando por uma ecologia integral, cuja essência é o reconhecimento da vinculação indissociável do social e ambiental. Que a desigualdade social é fator extremo que acelera a degradação, não havendo como obter a sustentabilidade sem superar a desigualdade mundial.

A ecologia integral é integradora e exige além da superação da desigualdade, uma mudança de rota, no modo de viver contemporâneo da cultura do descarte, superando-o, por uma cultura de resgate do modo de viver comunitário, dos saberes locais e da vida em harmonia com a natureza.

Após superar a desigualdade mundial, a ecologia integral ainda propugna por um consenso internacional acerca das características das normas internacionais, que devem perder o caráter do soft law, normas, desprovidas de sanção efetiva, e, portanto, sem eficácia material, de adesão facultativa, o documento papal, propõe a adesão obrigatória às normas ambientais e que estas venham acrescidas de duras sanções às nações que às descumprirem, pois o problema ambiental afeta a todos indistintamente sem respeitar fronteiras geográficas.

A novidade conjuntural, a partir da publicação da Encíclica Papal, que se refere a Terra como irmã, é exigência da construção de um novo paradigma há muito reclamado pelos ecologistas, que a superação da ideia da dominação humana da natureza, antes do colapso ambiental.

\section{REFERÊNCIAS}

AMARAL, Paulo Henrique. Direito Tributário Ambiental. São Paulo: Editora Revista dos Tribunais, 2007.

ANTUNES, Ricardo. Apresentando o livro de Mészáros, István. A crise estrutural do capital. 2. ed. ver. e ampliada. São Paulo: Boitempo, 2011.

BARRAL, Welber; FERREIRA, Gustavo Assed. Direito Ambiental e desenvolvimento. In: BARRAL, Weber; PIMENTEL, Luiz Otavio (Orgs.). Direito Ambiental e Desenvolvimento. Florianópolis: Fundação Boiteux, 2006.

BECK, Ulrich. A reinvenção da política: rumo a uma teoria da modernização reflexiva. In: BECK, Ulrich; GIDDENS, Antony; LADH, Scott. Modernização 
Reflexiva: política, tradição e estética na ordem social moderna. São Paulo: Editora da Universidade Estadual Paulista, 1997.

BESSA, Paulo, apresentando a obra de PASUKANIS, E.B. A Teoria Geral do Direito e o Marxismo. Rio de Janeiro: Renovar, 1989.

BOBBIO, Norberto. Teoria Geral da política: A Filosofia e as Lições Clássicas. Rio de Janeiro: Campus, 2000.

Liberalismo e Democracia. São Paulo: Brasiliense, 2007.

BOFF, Leonardo. A opção terra: a solução para a terra não cai do céu. Rio de Janeiro: Record, 2009.

CAMARGO, Ana Luiza de Brasil. Desenvolvimento Sustentável - dimensões e desafios. Rio de Janeiro: Papirus, 2003.

CHAUÍ, Marilena. O papel da Filosofia na Universidade. Rio de Janeiro: USU, $1988 . \quad$ Disponível em: http://www.professores.uff.br/seleneherculano/Textos/metodologia-das-cienciassociais2.pdf. Acesso em: 03/10/2011.

O que é ideologia. 30.ed.. São Paulo:Brasiliense, 1989.

CHOQUEHUANCA, David. Disponível em: http://planetasustentavel.abril.com.br/blog/planetaurgente/bolivia-cria-lei-mae-terra287125_post.shtml. Acesso em: 29/09/2011.

COASE, Ronald. The problem of social coast. Disponível em: http://www.ordemlivre.org/node/293. Acesso em: 02/09/ 2011.

DALY, Herman. A economia é um subsistema do ecossistema. Entrevista ao Instituto Humanitas Unisinos, da Universidade do Vale do Rio dos Sinos, de São Leopoldo - RS, em 15.08.2011.

DEMO, Pedro. Introdução à Metodologia da Ciência. São Paulo: Atlas, 1987.

DERANI, Cristiane. Direito Ambiental Econômico. São Paulo: Max Limonad, 2001.

ENGELS, Friedrich. A origem da família, da propriedade privada e do Estado. Rio de Janeiro: Civilização Brasileira, 1981.

Situação da Classe Trabalhadora na Inglaterra. Tradução de Rosa Camargo Artigas e Reginaldo Forti. São Paulo: Global, 1985.

FIORILlO, Celso Antonio Pacheco. Curso de Direito Ambiental. São Paulo: Saraiva, 2011.

FOLADORI, Guillermo. Limites do Desenvolvimento Sustentável. Tradução de Marise Manuel. Campinas: Editora da Unicamp, 2001.

FOSTER, John Bellamy. A ecologia de Marx: materialismo e natureza. 2.ed.. Rio de Janeiro: Civilização Brasileira, 2010. 
FRANCISCO, Papa. Encíclica Laudato si: Cuidando da Casa Comum. In: http://w2.vatican.va/content/francesco/pt/encyclicals/documents/papafrancesco_20150524_enciclica-laudato-si.html

FURTADO, Celso. O mito do desenvolvimento econômico. Rio de Janeiro: Paz e Terra, 1974.

GALEANO, Eduardo. Quatro mentiras sobre o meio ambiente. Disponível em: http://ponto.outraspalavras.net/2011/05/17/eduardo -galeano-aponta-quatro-mentirassobre-ambiente/. Acesso em: 13/09/2011.

GARCIA, Edmundo et al. Água - esperança e futuro. Disponível em: http://books.google.com.br/books?id=zksTliyuEWAC\&pg=PT48\&dq=\%C3\%A1 gua+e speran\%C3\%A7a+e+futuro\#v=onepage \&q\&f=false. Acesso em 02 set 2011.

GOIS, Antônio. Muvuca Planetária: Em outubro seremos 7 bilhões. Folha de São Paulo, Caderno Ilustríssima, p. 4, 14 ago. 2011. 2001, B.

Agora somos 7 bilhões. Folha de São Paulo, Caderno Mundo, p. A26, 30 out.

HABERMAS, Jurgen. A crise de legitimação no capitalismo tardio. Rio de Janeiro: Tempo Brasileiro, 1999.

HARDIN, Garret. Tragedy of the communs. Disponível em: http://www.garretthardinsociety.org/.../art_tragedy_of_the_communs. Acesso em: 04 set 2011 .

HARVEY, David. A produção capitalista no espaço. São Paulo: Annablume, 2005.

HAYEK, Friedrich A. Os fundamentos da Liberdade. São Paulo: Visão, 1983.

HOBSBAWN, Eric J. A era do Capital: 1848 - 1875. Rio de Janeiro: Paz e Terra, 1996.

A era dos extremos: o breve século XX: 1914 - 1991. São Paulo: Companhia da Letras, 1995.

Letras, 2000.

O novo século: entrevista a Antonio Polito. São Paulo: Companhia das

INTERGOVERNMENTAL Panel on Climate Change. Disponível em: http://www.ipcc.ch/pdf/supporting-material/expert-meeting-detectionanthropogenic-2009-09.pdf. Acesso em: 09/09/2011.

LEFF, Henrique. Racionalidade Ambiental: a reapropriação social da natureza. Rio de Janeiro: Civilização Brasileira, 2006.

Saber ambiental: sustentabilidade, racionalidade, complexidade e Poder.

3.ed.. Petrópolis: Vozes, 2001. 
LOWI, Michael. Ecologia e socialismo. São Paulo: Cortez, 2005. LOVELOCK,

James. A vingança de gaia. Rio de Janeiro: Intrínseca, 2006. MACHADO, Paulo

Afonso Lemes. Direito Ambiental Brasileiro. 9.ed.. São Paulo:

Malheiros, 2001.

MARÉS, Carlos Frederico. A função social da terra. Porto Alegre: Fabris Editor, 2003.

MARX; ENGELS. A ideologia Alemã. Coleção Obra Prima de Cada Autor. São Paulo: Martin Claret, 2004.

O Capital: edição popular. São Paulo: Martins Fontes, 1979.

O Capital: Crítica da economia política. Livro 1. Rio de Janeiro: Civilização Brasileira, 2011.

MELO, João Alfredo Telles. Direito Ambiental, luta social e ecossocialismo. Fortaleza: Edições Demócrito Rocha, 2010.

MÉSZÁROS, István. A crise estrutural do capital. 2.ed.. rev. e ampl. São Paulo: Boitempo, 2011.

. Para além do Capital: rumo a uma teoria da transição. Tradução de Paulo

Cezar Castanheira e Sergio Lessa. São Paulo: Boitempo Editorial, 2009.

MONTIBELLER-FILHO, Gilberto. O mito do desenvolvimento sustentável: meio ambiente e custos sociais no moderno sistema produtor de mercadorias. Florianópolis: Editora da UFSC, 2001.

O’CONNOR, James. ¿Es posible el capitalismo sostenible? In: Capitalism, nature, socialism" p. 4. Disponível em: http://www.iade.org.ar/uploads/c87bbfe5-a8b162cf.pdf. Acesso em: 03/10/2011.

OMM. PNUMA. Tercer informe de evaluación: Cambio climático 2001. Impactos, adaptación y vulnerabilidad. Resumen para responsables de políticas y Resumen técnico. Disponível em: http://www.ipcc.ch/pdf/climate-changes-2001/impact-adaptationvulnerability/ impact-spm-ts-sp.pdf. Acesso em 15 set 2011.

ONU. Acuerdos de Cancun. Disponível em: http://unfccc.int/meetings/cop_16/.php. Acesso em 04 set 2011.

OTT, Konrad. The case for strong sustainability. In: OTT, Konrad; THAPA, Phillipp (Eds.). Greifswald's Environmental Ethics. Greifswald: Steinbecker Verlag Ulrich Rose, 2003.

PÁDUA, Susana Machado. Afinal, qual a diferença entre Conservação ou Preservação? Disponível em: www.oeco.com.br. Acesso em: 26/07/2011.

PASUKANIS, Eugeny Bronislanovich B. A teoria geral do Direito e o marxismo. Rio de Janeiro: Renovar, 1989. 
PERRET, Bernand. O capitalismo é sustentável? São Paulo: Edições Loyola, 2011.

POLANYI, Karl. A grande transformação: as origens de nossa época. Rio de Janeiro: Campus, 1980.

RELATÓRIO Brundtland. Disponível em: www.scribd.com/Relatorio-BrundtlandNosso-Futuro-Comum-Em-Português. Acesso em: 09/08/2011.

SACHS, Ignacy. Caminhos para o desenvolvimento sustentável. Rio de Janeiro: Garamond, 2009.

Desenvolvimento: includente, sustentável, sustentado. Rio de Janeiro: Garamond, 2008.

SANTOS, Milton. Por uma outra globalização: do pensamento único á consciência universal. 19.ed.. Rio de Janeiro: Record, 2010.

SAROTTE, Georges. O Materialismo Histórico no Estudo do Direito. Lisboa: Editorial Estampa, 1972.

SEN, Amartyia. Desenvolvimento como liberdade. São Paulo: Companhia das Letras, 2000.

SERRES, Michel. O contrato natural. Rio de Janeiro: Nova Fronteira, 1991.

STEFANIAK, Jeaneth Nunes. Propriedade e função social: perspectivas do ordenamento jurídico e do MST. Ponta Grossa: Editora UEPG, 2003.

STEFANO, José Caetano da Silveira. Externalidades negativas: as abordagens neoclássica e institucionalista. Revista FAE, Curitiba, v. 9, jul/dez, 2006.

TERRA DE DIREITOS. Pagamento por serviços ambientais e flexibilização do código florestal para um capitalismo "verde". Disponível em: http://terradedireitos.org.br/wp-content/uploads/2011/08/Analise-PSA-CODIGOFlorestal-e-TEEB-_Terra-de-direitos.pdf. Acesso em 02 set 2011.

TIGAR, Michel e; LEVY, Madeleine R. O direito e a Ascensão do Capitalismo. Rio de Janeiro: Zahar Editores, 1978.

VEIGA, José Eli. A emergência socioambiental. São Paulo: Editora Senac, 2007.

Desenvolvimento sustentável: o desafio do século XXI. Rio de Janeiro: Garamond, 2010.

Desenvolvimento sustentável: que bicho é esse. Campinas, SP: Autores Associados, 2008. 